\title{
A EDUCAÇÃo DECOLONIAL E PAULO FREIRE NA PERSPECTIVA DA AVALIAÇÃO ESCOLAR
}

\author{
Rodrigo de Souza Pain ${ }^{1}$
}

\begin{abstract}
RESUMO
$\mathrm{O}$ artigo analisa aspectos centrais do processo avaliativo nas escolas brasileiras e aponta a ausência da perspectiva da decolonidade na prática docente. Todas as tensões sociais presentes em nossa sociedade tem reflexo no ambiente escolar, assim, percebe-se que na prática avaliativa se encontram elementos racistas que atuam fortemente na complexa relação professor/estudante. A cultura da violência, marca da nossa atual sociedade, e o descaso do poder público com a educação aumentam o cenário de estresse no espaço escolar. Diante das relações subjetivas da avaliação, indicamos que a prática meritocrática esconde grandes desigualdades no Brasil, encobre o racismo e não contribui para a redução das injustiças sociais na educação. Falta pedagogia continuada para professores e a discussão sobre avaliação não faz parte do cotidiano docente. Paulo Freire é lembrado e trazido nos teóricos da educação decolonial. A relevância deste trabalho está em trazer um tema crucial da educação brasileira.
\end{abstract}

Palavras-chave: Avaliação. Escolas Brasileiras. Educação Decolonial. Paulo Freire.

\section{DECOLONIAL EDUCATION AND PAULO FREIRE FROM THE SCHOOL EVALUATION PERSPECTIVE}

\begin{abstract}
The article analyzes central aspects of the evaluation process in Brazilian schools and points out the absence of the perspective of decolonization in this teaching practice. All the social tensions present in our society are reflected in the school environment, so we can see that in the evaluation practice there are racist elements that act strongly in the complex teacher / student relationship. The culture of violence, the mark of our current society, and the neglect of public power with education, increase the stress scenario in the school space. Faced with the subjective relations of evaluation, we indicate that the meritocratic practice conceals great inequalities in Brazil, covers up racism and does not contribute to the reduction of social injustices in education. There is a lack of pedagogy for teachers and the discussion about evaluation is not part of daily teaching. Paulo Freire is remembered and brought into the decolonial education theorists. The relevance of this work is to bring a crucial theme of Brazilian education.
\end{abstract}

Keywords: Evaluation. Brazilian Schools. Decolonial Education. Paulo Freire.

${ }^{1}$ Doutor em Ciências Sociais e Mestre em Desenvolvimento,Agricultura e Sociedade pela UFRRJ, Bacharel e Licenciado em Ciências Sociais e em História pela PUC/RJ. Professor do Instituto de Aplicação Fernando Rodrigues da Silveira da UERJ. Endereço eletrônico para contato: rodrigo.pain@gmail.com 


\section{EDUCACIÓN DECOLONIAL Y PAULO FREIRE DESDE LA PERSPECTIVA DE EVALUACIÓN ESCOLAR}

\section{RESUMEN}

El artículo analiza aspectos centrales del proceso de evaluación en las escuelas brasileñas y señala la ausencia de la perspectiva de descolonidad en la práctica docente. Todas las tensiones sociales presentes en nuestra sociedad se reflejan en el entorno escolar, por lo que está claro que en la práctica evaluativa hay elementos racistas que actúan fuertemente en la compleja relación profesor / alumno. La cultura de la violencia, una marca de nuestra sociedad actual, y el descuido de las autoridades públicas con la educación aumentan el escenario de estrés en el espacio escolar. En vista de las relaciones subjetivas de la evaluación, indicamos que la práctica meritocrática esconde grandes desigualdades en Brasil, esconde el racismo y no contribuye a la reducción de las injusticias sociales en la educación. Hay una falta de pedagogía continua para los maestros y la discusión sobre la evaluación no es parte de la rutina de enseñanza. Paulo Freire es recordado y llevado a los teóricos de la educación descolonial. La relevancia de este trabajo es plantear un tema crucial de la educación brasileña.

Palabras clave: Evaluación. Escuelas Brasileñas. Educacion Decolonial. Paulo Freire.

\section{INTRODUÇÃO}

Avaliar é um dos atos mais complexos da prática docente. Tal ação encontra-se no cerne da discussão acerca das competências e habilidades que os discentes devem adquirir durante a aprendizagem. Será que nossos professores estão preparados para esta tarefa? O que se tem feito para trazer à tona o debate a respeito das práticas avaliativas no contexto escolar? O presente artigo tem como objetivo apontar os caminhos que envolvem a discussão sobre avaliação e fomentar a discussão de uma temática muitas vezes esquecida nas instituições escolares.

O artigo 205 da Constituição Federal de 1988, ao assegurar diversos direitos sociais, é claro ao afirmar que "a educação é um direito de todos e dever do Estado e da família, será promovida e incentivada com a colaboração da sociedade, visando o pleno desenvolvimento da pessoa, seu preparo para o exercício da cidadania e sua qualificação para o trabalho” (BRASIL, 1988, art. 205). Dessa forma, a educação deveria servir como pilar de sustentação da sociedade brasileira, mas o que se tem observado é a diminuição contínua dos investimentos no setor, trazendo prejuízos no que diz respeito à qualidade ofertada para a população. Além disso, é preciso assinalar que a escola deixou de ser o único lugar de legitimação do saber. As novas tecnologias de informação e comunicação têm modificado as relações entre docentes e discentes bem como o às práticas de ensino. 
A metodologia utilizada na constatação de questões importantes que envolvem a avaliação e a educação brasileira em geral foi à revisão bibliográfica, depoimento de docentes e a observação participante - por meio de vasta experiência em diversos contextos escolares ao longo dos anos -, visando observar as perspectivas mais relevantes que tratam do tema. O método foi o hipotéticodedutivo buscando compreender aspectos da meritocracia enquanto ferramenta que alimenta as injustiças sociais em um país marcado pelas enormes desigualdades sociais e raciais. Assim, eliminamos a sedução que se esconde por trás da prática meritocrática ao apontar as relações subjetivas da avaliação e a colonialidade que muitas vezes persegue estudantes que representam segmentos historicamente marginalizados no Brasil.

\section{A AVALIAÇÃO NUMA PERSPECTIVA TEÓRICA}

Podemos apontar que é relativamente recente essa denominação de "avaliação" vinculada a uma prática até então chamada de "exame". Os exames escolares, tal como conhecemos e praticamos em nossas escolas, foram sistematizados no decorrer dos séculos XIV e XVII, junto a exigências da modernidade (LUCKESI, 2011)².

Buscar o conhecimento requer interação para além da sala de aula. Procura respeito, pede o convívio com outros sujeitos, partilhando experiências. Se o saber é relação - ligação no sentido de valor, relação de um tipo particular com o mundo, união consigo mesmo e com os outros -, "é o processo que leva a adotar uma relação de saber que deve ser o objeto de uma educação intelectual, e não a acumulação de conteúdos intelectuais” (CHARLOT, 2000). É preciso estar atento para o fato de que muitas escolas brasileiras estão apenas se empenhando em mostrar resultados, em avaliações externas, no sentido de prestar conta aos governos e sem prestar atenção ao processo e ao conteúdo efetivamente educacional e formativo.

Mediante tal afirmação, é relevante salientarmos que o processo educativo é complexo e fortemente delimitado por aspectos pedagógicos e sociais. Buscar uma educação inclusiva, tarefa de toda sociedade brasileira, é um difícil dever. Num grande trabalho de referência, o sociólogo Pierre Bourdieu (1992) aponta que a escola é, em grande medida, um instrumento de exclusão. Essa instituição converte desigualdades sociais em desigualdades escolares, cuja conseqüência é a reprodução das disparidades entre classes. Portanto, faz-se necessário apontar caminhos que tragam

\footnotetext{
${ }^{2}$ De acordo com o autor, a escola que conhecemos no presente é a escola da modernidade.
} 
debates às diferentes práticas de atuação docente. E a avaliação é, sem dúvida, uma das tarefas mais abrangentes que envolvem o magistério.

Entender o ato de avaliar parece tarefa simples aos olhos do senso comum. No Brasil, tradicionalmente, atribui-se uma nota de zero a dez ao estudante, a partir de um ou alguns instrumentos avaliativos, e a apreciação está dada. Alguns autores apontam a fragilidade com o que se verifica a ação de avaliar no país, muitas vezes resultado de uma espécie de negociação na qual o professor aproveita sua autoridade (ou até mesmo a falta dela) para intimidar os alunos, como salienta o educador e filósofo brasileiro Cipriano Luckesi (2011).

Percebe-se que muitos discentes desenvolvem medo e antipatia com o ambiente escolar, o que pode estar associado, dentre vários aspectos, a maneira como docentes utilizam a avaliação. $\mathrm{O}$ poder de dar uma nota não raramente é usado para induzir subordinação e controlar o comportamento do estudante em sala de aula (FERNANDES; FREITAS, 2007).

As notas aplicadas em caráter quantitativo passam a ser objeto de cobiça por parte de professores - de modo que muitos se orgulham quando boa parte dos discentes não consegue satisfatória pontuação -, e também de estudantes - que fazem qualquer coisa para uma boa contagem, independente de perspectivas lícitas. Luckesi (2011) chama esse contexto de "pedagogia do exame", o qual traz consequências. No campo pedagógico, é o não cumprimento da função de contribuir para a melhoria da aprendizagem. Na esfera psicológica, a tensão da nota traz personalidades submissas. A avaliação da aprendizagem utilizada de forma fetichizada ${ }^{3}$, segundo o autor, é útil ao desenvolvimento da autocensura. Por fim, há uma consequência no campo sociológico, pois a avaliação da aprendizagem realizada de tal modo acaba por servir ao processo de seletividade social.

É nessa direção que pensa o importante teórico suíço Philippe Perrenoud (1998), que destaca a crise de valores que vivenciamos e seu impacto no próprio sentido da escola. Segundo o autor, é através da prática da avaliação da aprendizagem que se fortalece a hierarquia da organização social. Existe uma espécie de relação de subordinação, em diferentes graus, e que também possui componentes sociais. Em escolas privadas percebe-se que muitas vezes os bolsistas são os que tiram as menores notas. Em entrevista com uma professora da rede privada, a mesma reconheceu que dá a nota em função da condição do aluno na escola: “eu seria leviana em não afirmar que sei quem são os alunos que pagam a mensalidade e aqueles que não pagam. Os

\footnotetext{
${ }^{3}$ Nesse caso fetiche é entendido como uma "entidade" criada pelo ser humano para atender uma necessidade e que se torna independente.
} 
primeiros são os meus clientes", afirmou a docente. A constatação é que a maioria dos alunos bolsistas é de origem negra, o que aponta para um forte componente racial, ou melhor, para o conceito de racismo institucional, como uma ideologia que desenvolve uma relação de hierarquias a partir da cor da pele, proporcionando uma estrutura de desigualdade social permanente na sociedade brasileira, limitando a população negra a ter acesso a seus direitos (WERNECK, 2013, p.17). Através da ação de avaliar, se classificam e distribuem as classes ou grupos sociais. A classificação dos alunos na sala de aula determina a hierarquia social. O sociólogo peruano Aníbal Quijano (2007) apresenta um modelo de análise do aspecto modernidade/colonialidade ${ }^{4}$, um desses modelos é a colonialidade do ser, no qual se afirma a superioridade da identidade masculina, heterossexual e branca e, de outra forma, a inferioridade da identidade negra, feminina, indígena, homossexual, ou qualquer identidade diferente do padrão estabelecido.

A pesquisadora Alzira Camargo (1997), ao analisar os discursos dos alunos sobre avaliação escolar e ao citar o filósofo francês Michel Foucault, chama atenção para as estratégias de dominação por meio da ocupação do espaço como: o enfileiramento, a imobilidade, a posição ocupada na ordem das cadeiras escolares, as filas dos fracos e dos fortes, o remanejamento de classes conforme o aproveitamento escolar, a definição do quadro negro para efeito de exercício da avaliação, e outras que sugerem o princípio do quadriculamento inspirado nas celas dos conventos e na vida em quartéis. Tal conjunto de práticas tem os mesmos propósitos: separar indivíduos torná-los solitários e impedir a ociosidade para melhor controlá-los e dominá-los ${ }^{5}$.

A prática do exame serve para medir e vigiar o desempenho dos estudantes a partir da nota que obtiveram bem como estabelece uma comparação entre o desempenho dos diversos alunos ${ }^{6}$. Para Foucault (2002), o exame ocupa uma função extremamente importante também porque expõe para o próprio indivíduo examinado o seu "verdadeiro eu". Como resultado das avaliações, os estudantes são classificados e objetivados. Porém, em contrapartida, esses indivíduos constroem suas identidades, na proporção em que esses objetivos são absorvidos por eles ${ }^{7}$.

\footnotetext{
${ }^{4}$ A colonialidade é uma forma de poder que surgiu do colonialismo moderno, e aponta uma hierarquia nas relações sociais pautadas na perspectiva de raça dentro do contexto capitalista. Assim, segmentos da sociedade que eram marginalizados e oprimidos no período colonial continuam nesse contexto de modernidade.

${ }^{5}$ A própria tendência de câmeras de vigilância nas escolas, e ultimamente na própria sala de aula é um exemplo.

${ }^{6}$ Vale salientar que a competição é característica cada vez mais presente na sociedade capitalista, principalmente em tempos de individualismo crescente.

${ }^{7}$ Michel Foucault analisa o poder não se identificando necessariamente com o Estado, mas nas várias instâncias da vida social e cultural, em uma perspectiva que o autor denominou como "metafísica do poder".
} 
Camargo (1997) percebe que os relatos dos alunos sobre a avaliação assentam-se na reação do professor diante do erro e do baixo rendimento dos estudantes. Dessa forma, um terço dos relatos dos discentes em sua pesquisa fez alusões a críticas destrutivas, ofensas morais, ameaças, gritos, perseguições, ridicularização, discriminação, todas praticadas em nome da avaliação. A própria ideia de estigma se faz presente como rótulo social negativo que identifica pessoas (ou no caso estudantes) como desviantes, não porque seu comportamento viole normas, mas porque eles têm características pessoais ou sociais que os levam à exclusão (GOFFMAN, 1963).

Isso nos leva à percepção de que para muitos professores a avaliação é um momento em que sua autoridade é reforçada, atentando, inclusive, contra o artigo $7^{\circ}$ da Declaração Universal dos Direitos Humanos, segundo a qual: todos são iguais perante a lei e tem direito, sem qualquer distinção, a igual proteção da lei. Todos tem proteção contra qualquer discriminação que viole a presente Declaração e contra qualquer incitamento a tal discriminação (DUDH, 1948: 06).

Vale salientar, ainda, que em diversas realidades sociais do Brasil a cultura da violência está fortemente inserida. Muitas vezes a relação docente/discente é pautada por essa característica ${ }^{8}$. Igualmente, muitos professores por nós entrevistados relataram sofrer, em menor ou maior grau, a Síndrome do Burnout, ou seja, a exaustão extrema com precariedade do estado físico, emocional e mental por conta da sua atividade em sala de aula ${ }^{9}$. A falta de políticas públicas que facilitem a convivência e a harmonia escolar está no cerne da complexa relação entre discentes e docentes em um país caracterizado pela cultura do medo e pela violência.

\section{AS RELAÇÕES SUBJETIVAS QUE PERMEIAM A AVALIAÇÃO}

$\mathrm{Na}$ escola a avaliação tem um papel decisivo no que diz respeito ao desenvolvimento cognitivo do aluno e de suas perspectivas de aprendizagem. No entanto, percebe-se que a salutar discussão sobre o tema passa distante da maioria dos docentes. Faltam cursos de educação

\footnotetext{
${ }^{8}$ Luckesi diz que há algum tempo não existem castigos físicos nas escolas brasileiras, por outro lado, o castigo não desapareceu da escola, pois ele se manifesta de outras maneiras, que não atingem o corpo físico do aluno, mas sua personalidade(2011:190)

${ }^{9}$ De acordo com a agência alemã Deutsche Welle, ao citar um ranking de violência nas escolas elaborado pela Organização para a Cooperação e Desenvolvimento Econômico (OCDE - 2014), o Brasil lidera as estatísticas. Com mais de 100 mil professores e diretores de escolas do segundo ciclo do Ensino Fundamental e do Ensino Médio (alunos de 11 a 16 anos), considerando dados de 2013, 12,5\% dos docentes brasileiros ouvidos relataram ser vítimas de agressões verbais ou de intimidação de alunos ao menos uma vez por semana. A média entre os 34 países pesquisados é de 3,4\%. Disponível em: <https://www.dw.com/pt-br/a-viol\%C3\%AAncia-contra-professores-no-brasil/a48442455>, acesso em: 29 de maio de 2019.
} 
continuada em maior parte dos sistemas de ensino do país, incorrendo na solidão do professor, muitas vezes sozinho, abandonado e fragilizado para desenvolver a ação de avaliar seu alunado.

Em diversos momentos da prática docente podemos perceber formas subjetivas de avaliação, o que implica no questionamento de uma possível visão técnica. Nem sempre o professor avalia apenas o conhecimento que o estudante adquiriu em um determinado processo de aprendizagem, mas também valores e atitudes. Ao conceituarmos a avaliação escolar devemos levar em consideração que são diversos os aspectos incluídos nesta definição: o conhecimento assimilado pelo estudante e seu desenvolvimento, assim como o comportamento do discente com seus valores e comportamentos (FERNANDES e FREITAS, 2007).

Dessa maneira, os juízos de valor muitas vezes dão a base da avaliação e são comprovados pela opinião pessoal do professor, por aquilo que ele valoriza, por suas simpatias, identificação ou antipatias em relação ao discente, por seus preconceitos, por suas concepções e crenças (ANDRÉ e PASSOS, 1997). Esta contaminação se conhece como "efeito halo" que consiste na interferência que produz a opinião que se tem sobre alguns aspectos de uma pessoa no sentido da apreciação ou não de suas qualidades (CAREAGA, 2001). Tal efeito, muito estudado no campo empresarial, é pouco analisado na prática pedagógica. O clima de estresse e abandono que muitos professores estão submetidos ajuda a reforçar esses aspectos negativos dos estudantes.

Pierre Bourdieu (2001) chama de violência simbólica a ação pedagógica que é objetivamente estruturada e impõe um arbitrário cultural de um grupo de classe a outro grupo de classe. Diversos elementos incorporam a sensação de avaliação, anulando a perspectiva de avaliação neutra ${ }^{10}$. Como observa Gimeno Sacristán, catedrático da Universidade de Madri, alguns docentes valorizam a capacidade de argumentação do aluno, outros a resposta correta, uns a ortografia, outros a expressão escrita, alguns o conceito, outros docentes a técnica. Isso é um efeito das percepções humanas, e é delas que se nutre à avaliação (SACRISTÁN apud ANDRÉ e PASSOS, 1997).

\section{PAULO FREIRE E A PERSPECTIVA DECOLONIAL}

É mister apontar a importância das obras de Paulo Freire nos autores decoloniais. O educador brasileiro influenciou diversos pensadores em variados campos do conhecimento, em especial a pedagogia crítica. A educação libertadora, trazida por Freire, aponta que o universal não é superior ao local, ao contrário, o primeiro surge das inúmeras práticas locais e do seu

\footnotetext{
${ }^{10}$ Como na frase atribuída a Paulo Freire, mas sem observação bibliográfica, "Não existe educação neutra, toda neutralidade afirmada é uma opção escondida".
} 
processamento, ou seja, o local é redescoberto, modificado, enriquecido e adaptado em cada ato de recriação do conhecimento ${ }^{11}$ (Gerhardt, 2001:104). E a educação popular, que trouxe significativas reflexões sobre os sujeitos colocados à margem da sociedade capitalista, no qual o oprimido deve sair dessa condição de opressão a partir do estímulo da consciência de classe oprimida. Esses dois pontos que nos interessa ao refletir sobre a educação decolonial. ${ }^{12}$

Da mesma forma que o clássico livro de Paulo Freire "Pedagogia do Oprimido" apresenta maneiras de desconstruir o mito da estrutura opressora, o ponto de vista decolonial caracteriza diferentes estratégias para a desconstrução da narrativa eurocêntrica. A obra de Freire converge com algumas das principais matrizes críticas de pensamento latino-americano dos últimos anos. De acordo com Camila Penna, a proposta da perspectiva decolonial, tem assim, como a obra de Freire, um valor pedagógico na medida que questiona os referenciais eurocêntricos a partir dos quais o conhecimento na área das ciências sociais é produzido (2014) A autora apresenta diferentes estratégias para reverter a "colonização do ser" que aparecem tanto em Freire como nos autores pós-coloniais, como revolução, objetivação da mitologia opressora (ou eurocêntrica), deslocamento do lugar de fala, e valorização do conhecimento fronteiriço (PENNA, 183:2014).

Em sua obra, "Cartas à Guiné-Bissau”, Freire relata experiências de suas visitas aquele país africano com o propósito de alfabetização da população local sem a perspectiva da educação colonialista, “[...] porque a Guiné-Bissau não parte do zero, mas de suas fontes culturais e históricas, de algo de bem seu, da alma mesma de seu povo, que a violência colonialista não pode matar”(Freire, 1978:10). O próprio autor também salienta que, “[...] a educação colonial herdada, de que um dos principais objetivos era a " "desafricanização" dos nacionais, discriminadora, mediocremente verbalista..." (1978:15). Assim, Freire busca a superação de um passado recente opressor olhando para a própria realidade, múltipla e complexa da população guineense.

\footnotetext{
${ }^{11}$ Segundo o Heinz-Peter Gerhardt (2001), pode-se afirmar que a educação libertadora é um dos poucos conceitos educacionais do Hemisfério Sul adotado por educadores do Norte.

${ }^{12}$ A autora também aponta para os pressupostos e argumentos da obra de Freire que convergem com a literatura decolonial, tais como o raciocínio dialético, a ideia de "colonização cognitiva", e o argumento de que a dominação (e a estrutura opressora) se fundamenta em mito (do eurocentrismo).
} 


\section{A MERITOCRACIA, A COLONIALIDADE E A NECESSIDADE DO DEBATE DOCENTE}

Após entrevistas com professores, foi simples observar que as discussões que envolvem a prática avaliativa nas escolas brasileiras esbarram na visão meritocrática ${ }^{13}$. Os termos "meritocracia" ou "valorização do mérito", embora seduzam num primeiro momento, escondem as complexas e diversas realidades sociais. Para Pierre Bourdieu (1983), os conceitos tem o poder de criar a realidade, e nesse caso, a meritocracia serve para mascarar a desigualdade e as diferentes oportunidades que envolvem os estudantes avaliados. Podemos trazer o conceito de colonialidade para compreender melhor a argumentação. É importante ter em mente que o colonialismo não acabou com a independência. De acordo com Aníbal Quijano (2000), a colonialidade do poder é classificação social da população mundial ancorada na noção de raça, que tem origem no caráter colonial, mas já provou ser mais duradouro e estável que o colonialismo histórico, em cuja causa foi determinada. Entender o Brasil como um país miscigenado, marcado por séculos de escravidão da população de origem africana parece ser chave para compreender que a avaliação escolar também carrega os preconceitos, inclusive racial, no seu cerne.

A formação inicial do professor, do ponto de vista tradicional, é uma educação que visa reproduzir e perpetuar o monoculturalismo, a despersonalização, o aculturamento e que enxerga a diversidade cultural como obstáculo ao processo educacional ${ }^{14}$ (LEGRAMANDI E GOMES, 2019:28). Em nossa sociedade existem práticas (como o processo avaliativo nas escolas), tradições e histórias que sofrem profundo preconceito dos setores hegemônicos, isto é, aqueles que se aproximam do que é considerado "correto" por parte daqueles que tem o poder. Muitas vezes essas práticas também são desenvolvidas no campo da educação popular, o que torna mais necessário trazer à baila essas questões.

Percebe-se que a maioria dos professores no âmbito da educação básica concorda com a negação do princípio da meritocracia justamente pelas desigualdades que atingem todo o processo educacional. A meritocracia é um mito que alimenta as desigualdades, e isso tem impacto na academia, pois um assunto no qual a universidade é bastante carente diz respeito a uma reflexão conjunta sobre que tipo de conhecimento ela deve produzir e para quem são esses conhecimentos

\footnotetext{
${ }^{13}$ Perspectiva na qual o sucesso do indivíduo depende exclusivamente do seu mérito, como talento, esforço, habilidade ou expertise. Segundo seus críticos, séculos de desigualdades e opressão levaram as minorias sociais a um contexto de desvantagem, portanto sem os privilégios da classe dominante. No caso brasileiro, as enormes desvantagens da classe dominada refletem historicamente em quaisquer indicadores sociais.

${ }^{14}$ Basta perceber a pouquíssima valorização dos autores negros, e de países em desenvolvimento nos diversos currículos dos cursos de formação de professores.
} 
(CHALHOUB, 2007). Um exemplo é a pouca importância dada ao ensino de História da África no Brasil, inclusive nos currículos de ciências humanas. Num país com mais da metade da população afrodescendente é fundamental repensar conteúdos e necessidades. A visão eurocêntrica da história ainda é uma realidade, seja nas universidades ou nas escolas ${ }^{15}$. É fundamental a busca por teóricos da educação decolonial, pois boa parte da população negra brasileira não se vê representada por autores brancos. Segundo a professora da Universidade Nacional de Salta, na Argentina, Zulma Palermo:

Optar por uma posición decolonial que ejerce resistência ante esse estado de situación, implica localizarse em um lugar de indidable lucha intelectual y significa también la imprescindible necesidad de debatir com otras maneras de concebir la resistência a la dominación por el poder[...](PALERMO, 2010, p.50)

Sabemos que a desigualdade social se reflete profundamente na educação. Num enfrentamento a essa realidade, universidades públicas e diversos concursos brasileiros consagram princípios de ação afirmativa, buscando, assim, proteger minorias sociais e segmentos marginalizados historicamente. Esse é um reconhecimento cabal que o princípio meritocrático, no campo avaliativo, tem que ser repensado, contextualizado e criticado, ainda que vivenciemos uma expansão social do conservadorismo que traz consigo a negação das ações afirmativas e uma fantasiosa valorização da meritocracia. Dessa forma, a meritocracia ocupa um importante lugar nesse projeto de educação. Isto porque é esse paradigma que, ao mesmo tempo, encobre as histórias de dominação e subordinação denunciadas pela educação decolonial, também que justifica os "fracassos" escolares de determinados sujeitos ou coletivos sob a defesa de que não fizeram por merecer esse lugar, portanto não estando aptos ou preparados (Leite, Ramalho e Carvalho, 2019).

Apesar do discurso contrário a questão meritocrática por parte dos professores, o que se percebe nos bancos escolares é a continuação dessa prática. Contribui de maneira importante nessa direção à falta de estrutura que caracteriza grande parte das escolas públicas brasileiras, principalmente no que diz respeito à ausência de funcionários com qualificação técnica, tais como pedagogos, assistentes sociais e psicólogos. A diminuição dos investimentos públicos em educação é um fator determinante para a observação desse contexto.

$\mathrm{Na}$ avaliação escolar, o professor brasileiro geralmente não tem o suporte técnico administrativo institucional para compreender o cotidiano do alunado para além dos seus encontros em sala de aula. Mesmo convivendo com o estudante, na maioria das vezes não conhece sua

\footnotetext{
${ }^{15}$ A Universidade brasileira, que deve ter em sua missão a busca pelo civismo republicano, é marcada historicamente pela exclusão de diversos segmentos da sociedade do país.
} 
história, seus problemas, seu cotidiano, suas demandas, enfim, todo o seu lado humano e social. Ainda temos professores com baixos salários e que precisam lecionar em várias instituições escolares para complementar a renda, bem como salas de aulas cheias. Muitos estudantes significam impossibilidade estrutural de aplicação de uma avaliação individualizada. Como agravante, a maior parte das escolas não dispõe do Projeto Pedagógico, e assim as avaliações ficam restritas a particularidades do docente. Ao avaliar o corpo discente, o professor acaba desenvolvendo métodos que tratam a coletividade dos alunos e acabam utilizando instrumentos meritocráticos incapazes de observar as particularidades individuais.

A construção de um projeto pedagógico mais condizente com a situação social e histórica do estudante pode ser medida pelos processos avaliativos desenvolvidos pela instituição escolar (MANTOVANI, 2006). Uma escola que não possui o plano pedagógico é uma instituição que não se conhece. Dessa forma, é fundamental o desenvolvimento de políticas públicas com a visão de fortalecer o "staff" educacional das escolas, e encarar esse corpo de técnicos como imprescindível no processo educativo. A qualidade de ensino resulta do envolvimento de todos os participantes da estrutura educacional ${ }^{16}$. Desta maneira, central ao projeto político-acadêmico da decolonialidade é o reconhecimento de múltiplas e heterogêneas diferenças coloniais, destarte como as múltiplas e heterogêneas reações das populações e dos sujeitos subalternos à colonialidade de poder (COSTA e GROSFOGUEL, 2016).

\section{CONSIDERAÇÕES FINAIS}

Este artigo teve como intuito refletir sobre a prática avaliativa no contexto escolar brasileiro, com contribuições do pensamento decolonial e de Paulo Freire. O princípio da colonialidade se faz presente na escola como instituição em diversas maneiras, inclusive na avaliação, no qual o racismo institucional ainda persiste. Entendo que a decolonialidade deve ser uma prática social constantemente debatida no âmbito escolar e também nos cursos de formação de professores. A cultura da violência e a recente e difícil conjuntura política brasileira, marcada por perseguições a docentes e desvalorização de conquistas históricas da educação brasileira como a liberdade de

\footnotetext{
${ }^{16}$ Um exemplo é o inspetor escolar, um profissional que não deve cuidar somente da parte burocrática, mas também procurar um método de trabalho menos controlador, tornando-se mais participativo e democrático, mais orientador da aplicação da norma e mais estimulador da criticidade e da criatividade tão necessária à melhoria do funcionamento do sistema (SANTANA e NUNES, 2011).
} 
cátedra também assinala esse cenário de tensão que se reflete na relação entre docentes e estudantes.

Há uma necessidade na valorização da equipe escolar que representa a busca pela qualidade de ensino, o que impacta, em última instância, num processo mais humanitário de avaliação. Técnicos administrativos, psicólogos, assistentes sociais, entre outros profissionais representam muito na melhoria do ensino. Faltam profissionais, e isso tem impacto direto na relação entre professor e estudante - marcada pela inquietação por ambos os lados. A busca por uma educação inclusiva e humanizada passa necessariamente pelo reforço da equipe escolar.

A avaliação deve levar em conta as particularidades e necessidades dos alunos de maneira individualizada. Deve ser formativa, valorizando um processo contínuo, ou seja, no dia-a-dia da sala de aula, com todos os agentes escolares envolvidos. A prática da meritocracia deve ser repensada no desenvolvimento escolar que tem como objetivos a educação inclusiva e decolonial.

Os estudantes devem ser pensados dentro de sua complexidade como indivíduo pertencente a um conjunto social de maneira democrática e libertária. Também salientamos que a ausência de políticas públicas que facilitem o convívio escolar é uma importante lacuna que está no cerne da tensa relação entre professores e estudantes e que se refletem na prática educativa, inclusive na atividade avaliativa. Devemos buscar, dessa maneira, uma educação libertadora democrática pensando a partir dos sujeitos e suas identidades sociais.

\section{REFERÊNCIAS BIBLIOGRÁFICAS}

ANDRÉ, M.E.D.A; PASSOS, L. F. "Para além do fracasso escolar: uma redefinição das práticas avaliativas”. In: Aquino, Julio Groppa. Erro e fracasso na escola. Alternativas teóricas e práticas. São Paulo: Summus, 1997.

DUDH. ASSEMBLEIA GERAL DA ONU. Declaração Universal dos Direitos Humanos. Paris, 1948. Disponível em: https://nacoesunidas.org/wp-content/uploads/2018/10/DUDH.pdf.

BOURDIEU, P. A reprodução. Rio de Janeiro: Francisco Alves, 1992.

BOURDIEU, P. Questões de Sociologia. Rio de Janeiro: Marco Zero, 1983.

BOURDIEU, P. Meditações pascalianas. Rio de Janeiro: Bertrand Brasil, 2001.

BRASIL. Constituição Federal de 1988. Org. Yussef Said Cahali. 9.ed. rev., ampl. e atual. São Paulo: Editora Revista dos Tribunais, 2007.

CAMARGO, A. L. C. "O discurso sobre a avaliação escolar do ponto de vista do aluno". Revista da Faculdade de Educação, Universidade de São Paulo, v. 231(1- 2), pp. 283-302, 1997.

CAREAGA, A. La evaluación como herramienta de transformación de la prática docente. Universidade de los Andes, Mérida: Educere, 2001. 
CARVALHO, José Murilo. Cidadania no Brasil: o longo caminho. Rio de Janeiro: Editora Civilização Brasileira, 2001.

CHALHOUB, S. A meritocracia é um mito que alimenta as desigualdades. In: Jornal da Unicamp, 7 de jun. 2007. Disponível em:

https:/www.unicamp.br/unicamp/ju/noticias/2017/06/07/meritocracia-e-um-mito-que-alimentadesigualdades-diz-sidney-chalhoub acesso em: 29 de maio de 2019.

CHARLOT, B. Relação com o saber-elementos para uma teoria. Porto Alegre: Artes Médicas, 2000.

COSTA, J.B.;GROSFOGUEL,R. "Decolonialidade e perspectiva negra”. Sociedade e Estado. Brasília, v.31., n.1, 2016.

FERNANDES, C. O; Freitas, L.C. Indagações sobre currículo: currículo e avaliação. Brasília: Ministério da Educação, Secretaria de Educação Básica, 2007.

FOUCAULT, M. Vigiar e punir: o nascimento da prisão. Petrópolis: Vozes, 2002.

FREIRE, P. Cartas à Guiné-Bissau. Rio de Janeiro: Paz e Terra, 1978

GERHARDT, H.P. “Educação libertadora e globalização”. In FREIRE, A.M.A (org.). A pedagogia da libertação em Paulo Freire. São Paulo: Editora Unesp, 2001.

GOFFMAN, E. Stigma - Notes on the management of spoiled identity. New Jersey: PrenticeHall, 1963.

LEGRAMANDI, A.B;GOMES, M.T. "Insurgência e resistência no pensamento freiriano: propostas para uma pedagogia decolonial e uma educação emancipatória". Revista Ambiente e Educação. São Paulo, USP, v.12, n.1, pp.24-32, 2009.

LEITE, L.H.A., RAMALHO, B.B.M.,CARVALHO, P.F.L. A educação como prática de liberdade: uma perspectiva decolonial sobre a escola. Educação em Revista. Belo Horizonte, v.35, 2019.

LUCKESI, C. Avaliação da aprendizagem escolar: estudos e proposições. 14. ed. São Paulo: Cortez, 2011.

MANTOVANNI, E.E. A avaliação no ensino de História e as contribuições da psicopedagogia. Universidade de Campinas, 2006.

OCDE. TALIS 2013. Results: An international perspective teaching and learning. OECD, Paris, 2014.

PARLERMO, Z. "La Universidad Latinoamericana em la encrucijada decolonial”. Revista de Estudos Críticos. Universidade Nacional del Comahue, n.1, ano, 1, 2010.

PERRENOUD, P. Avaliação: da excelência à regularização das aprendizagens: entre duas lógicas. Porto Alegre: Artmed, 1998.

QUIJANO, A. “Colonialidad del poder y clasificacíon social”. In CASTRO-GÓMEZ, S.; GROSFOGUEL, R.(Org.) El giro decolonial: reflexiones para uma diversidad epistémica mas allá del capitalismo global. Bogotá: Siglo del Hombre Editores, 2007, pp.93-127.

QUIJANO, A. “Colonialidad del poder y clasificacíon sócial”. Journal of World Systems Research. Vol. XI, n.2, 2000, pp.342-386. 
Pain; $R$ de $S$.

SANTANA, K.E.S; NUNES, S.C. Inspeção escolar no processo motivacional suas implicações e importância na educação. Faculdade Católica de Uberlândia, 2011.

WERNECK, Jurema. Racismo institucional. São Paulo: Ibraphel Gráfica, 2013. 